\title{
My experiences with Elisabet Helsing
}

I first met Elisabet Helsing at a historic meeting on baby food advertising in Berne Switzerland in July 1976, continuing our conversations while meeting with other groups in Sweden and Norway. At that time, she had convinced Norway to start what became a long battle with FAO to get breast milk added to their Food Balance Sheets. (This never succeeded.) As part of that process, NORAD offered funds to FAO to support breastfeeding promotion projects. WHO reacted negatively, insisting that breastfeeding was their territory. A compromise was found, and FAO agreed to limit itself to the economic issues involved. Stina Almroth and I were hired in 1977 to do research on the economics of breastfeeding in West Africa. This was published in book form in 1979 by FAO in both English and French versions; in the following years we were informed that this was their "best seller."

Also in 1979, Elisabet sent to Stina Almroth (by then, my wife) and I a draft for the English translation of her manual "Breastfeeding in Practice," asking for our inputs. Though I had been working with some aspects of breastfeeding at public health level since 1974, the clinical information in her manual was a learning experience. My first child was born in Ekenäs, Finland in 1979. At four days of age, we boated out to an isolated island where my wife's family had a summer home. The next day, my wife began suffering from such severe breast distention that she feared she would have to stop breastfeeding. Desperately I searched through the unbound pages of the draft manual and was inspired by its information to hold the baby above his supine mother, taking pressure off her breasts and allowing him to suckle upward. This worked well and from then on there were no breastfeeding problems. One example among thousands I believe where Elisabet's expertise came to the rescue!

Elisabet and I met many times in international meetings after that, including a few times after she began suffering from Parkinson's Disease. Her courage in speaking in front of large groups with that affliction was stunningly. She was always a staunch supporter of measures to protect, support and promote breastfeeding and a contributor to the work of the World Alliance for Breastfeeding Action (WABA), which has posted a notice about her life and work here: http://waba.org.my/honouring-the-life-of-dr-elisabet-helsing/

She will be missed by many around the world.

--Ted Greiner 